\title{
Mindful schools: Neuropsychological performance after the implementation of a mindfulness-based structured program in the school setting
}

\author{
Annabel Folch ${ }^{1,2}$ (D) Laia Gasol $^{1} \cdot$ Luis Heredia $^{1,3,4} \cdot$ Paloma Vicens $^{1,3,4} \cdot$ Margarita Torrente $^{1,3,4}$
}

Accepted: 24 November 2021

(C) The Author(s) 2021

\begin{abstract}
Mindfulness has attracted considerable attention in educational settings as it can have positive effects on children. However, the role of mindfulness practice in schools has yet to be understood. The aim of the present study is to assess the impact of mindfulness on neuropsychological performance and psychological well-being of primary school children. It also aims to explore the teacher's mindfulness training effect on the intervention. The present study recruited 100 children (64\% girls and $36 \%$ boys) aged 9-11 from a primary school in Tarragona (Spain). The research was conducted between 2016-2018 with three experimental groups: a mindfulness intervention group with a trained mindfulness teacher, a mindfulness intervention group with a non-trained mindfulness teacher, and a control group. All groups were evaluated before and after a 13-weeks intervention, consisting of 5-10 min mindfulness daily sessions before class. After the intervention, the two groups of children receiving mindfulness sessions performed better than controls in several neuropsychological tasks involving executive functions, such as short-term and working memory, learning, mental flexibility, visuospatial abilities and processing speed. No significant differences were found in the assessment of daily stress or emotional and behavioural problems. The findings of the present study can contribute to a better understanding of the role of mindfulness practice in primary children regarding neuropsychological performance, highlighting the importance of the teacher's mindfulness training in the teaching/ learning process.
\end{abstract}

Keywords Mindfulness $\cdot$ Executive functions $\cdot$ Primary Schools $\cdot$ Children $\cdot$ Teacher

\section{Introduction}

Mindfulness can be defined as a psychological state of awareness and also, the practices that promote this awareness, as well as a mode of processing information, and a character trait (Medical Subject Headings, 2014). As a

Margarita Torrente

margarita.torrente@urv.cat

1 Department of Psychology, School of Educational Sciences and Psychology, Universitat Rovira i Virgili, Tarragona, Spain

2 UNIVIDD - Fundació Villablanca, IISPV, CIBERSAM - Centro de Investigación Biomédica en Red, Reus, Spain

3 Laboratory of Toxicology and Environmental Health, School of Medicine, IISPV, Universitat Rovira i Virgili, Reus, Spain

4 CRAMC (Research Center for Behavior Assessment), Universitat Rovira i Virgili, Tarragona, Spain practice, it originates from ancient eastern philosophies and traditional Buddhist meditation (Ie et al., 2014; Ven. Bhikkhu Bodhi, 2016).

In recent years, researchers have shown an increased interest in this topic. Several studies have demonstrated that mindfulness training reduces stress levels (Greeson et al., 2018; Khoury et al., 2015; Pascoe et al., 2017), moderates anxiety and depression symptoms (Hofmann \& Gómez, 2017; Hofmann et al., 2010), and facilitates emotion regulation (Guendelman et al., 2017; Remmers et al., 2016; Wheeler et al., 2017). Mindfulness can also bring improvements in physical symptoms, such as blood pressure reduction (Brenner et al., 2020), improved sleep quality (Gong et al., 2016; Rusch et al., 2019) and alleviated gastrointestinal difficulties (Aucoin et al., 2014; Kearney et al., 2011); among other health benefits (Creswell et al., 2019; Dahlgaard et al., 2018; Grossman et al., 2004).

Since the early 2000s, there is a growing body of literature that recognises the positive role of mindfulness 
practice implementation in educational settings and children, including stress relief, self-care, emotional response modulation, cognitive performance, academic success and classroom engagement (Deng et al., 2019; Felvert et al., 2016; Heredia et al., 2020a, b; Renshaw \& Cook, 2017; Schonert-Reichl \& Roeser, 2016; Zoogman et al., 2015; Zenner et al., 2014). It should be also pointed out that there is a growing and promising quantitative evidence base on the need for teachers to learn mindfulness themselves to cultivate mindfulness in schools effectively (Hirshberg et al., 2020; Weare, 2019).

In particular, educational settings are a focus of interest for mindfulness because it may have a positive impact on the children's neuropsychological performance and psychological well-being. Regarding the last, a recent literature review found an adequately evidence base on the psychological, mental and social health and well-being of the young (Weare, 2019). Another review of twenty-four studies suggested that school based mindfulness interventions were able to improve cognitive performance and resilience to stress (Zenner et al., 2014). A study about the effect of those interventions on quality of life for elementary school students and teachers found a significant improvement in emotional and psychosocial quality of life, suggesting that mindfulness interventions may improve symptoms of anxiety and can facilitate stress management (Bazzano et al., 2018). An additional study found a positive effect of mindfulnessmeditation on several children's psychological well-being dimensions and a reduction of attention problems (Crescentini et al., 2016).

As for neuropsychological performance, mindfulness is an increasingly popular approach to executive functions skills training (Semenov et al., 2020). Executive functions encompass domain general cognitive processes associated with working memory, inhibitory control, and attention shifting, and are core contributors to school success (Blair, 2016). The scarce research to date suggests that mindfulness-based interventions are a promising approach to targeting attention and executive function in children and adolescent (Mak et al., 2018), indicating that children who are more mindful are also less likely to experience difficulties with inhibitory control, working memory, and attention shifting (Cordeiro et al., 2021; Geronimi et al., 2020).

Nevertheless, research on mindfulness for young students is very promising but has been conducted in limited populations, and with great heterogeneity among studies (Sibinga et al., 2016; Zenner et al., 2014). In addition, up to now, very little research has been carried out on this topic in Spain. The research in schools has tended to focus on the validation of standardised measures, such as the Child and Adolescent Mindfulness Measure (CAMM) (Guerra et al., 2019), or the Child and Adolescent Mindfulness Measure (Viñas et al., 2015), among other instruments (Calvete \& Royuela-Colomer, 2016). In contrast, very few studies have systematically evaluated the implementation of mindfulness programs in Spanish schools and their benefits in the psychological and neuropsychological areas. A recently published article assessed the effectiveness of a mindfulness-based programme on school adjustment, school behavioural problems and school outcomes in 118 Spanish elementary education students, reporting an improvement in all these areas (Moreno-Gómez et al., 2020). It is interesting to note that the programme was implemented during school hours by the staff teachers with the support of an expert and external instructor. Another study conducted by the same authors implemented a mindfulness-based program based on social-emotional learning in 74 kindergarten children. The findings indicated that there was a significant reduction in the scores of global maladaptive dimensions, and a significant increase in both visual perception and attention performances. Moreover, children increased their scores of global and non-verbal development (Moreno-Gómez \& Cejudo, 2019). As in the previously mentioned study from the same authors, all sessions were conducted by the kindergarten teachers with the aid of an external assistant from the research team. Yet another recent study examined the effectiveness of a mindfulness-based intervention on variables related to classroom social environment in 83 students aged 11-13, finding an improved classroom social environment and impulsivity self-regulation (Pinazo et al., 2020). Again, the mindfulness programme took place during school time and was led by a mindfulness formed teacher who worked there.

Overall, the promising results of these few studies highlight the need for in-depth studies to provide more reliable evidence about this matter in Spain. Moreover, there are no studies analysing the possible differential effects when the program is delivered by a mindfulnesstrained teachers compared to untrained teachers. For these reasons, the main aim of the present study is to assess the effects of a mindfulness-training structured program on the neuropsychological performance (memory, attention, and executive functions) and psychological well-being (stress levels and emotional/behavioural problems) on children aged 9-11 attending primary school in Tarragona (Spain). This study also aims to explore the effect of the teacher's mindfulness training on the intervention. Thus, the main hypothesis of the present study is that primary school children who followed a mindfulness -based program in the school timetable hours would improve their neuropsychological performance and psychological well-being, and this benefit would be even greater if a mindfulness-trained classroom teacher delivers the program. 


\section{Methods}

The present study utilised a control-group and two experimental groups following a pre-test post-test design. All procedures were approved and performed in accordance with the standards of the Hospital Sant Joan de Reus and Hospital Joan XXIII de Tarragona ethical research committees (code number: 15-01-29/1proj1), as well as the 1964 Helsinki Declaration and its later amendments. Informed consent was obtained from the parents/tutors of all participants involved in the study.

\section{Sample}

A sample of 100 children was recruited from a primary school in Tarragona (Spain). They were fifth or sixth graders born between January 2005 and December 2007, with a mean age of 10.37 years $(\mathrm{SD}=0.525)$. Regarding gender distribution, $64 \%$ were girls and $36 \%$ boys.

Eligibility criteria required individuals to be aged 9 to 11 , with regular school attendance and written informed consent. This age group was selected taking into account factors such as the participant's attention span, cognitive capacities and language level, as well as the availability and the adequacy of valid mindfulness exercises and reliable assessment tools for the target age group.

\section{Procedures}

The research was conducted between September 2016 and March 2018 with three Six Grade classes and three Fifth Grade classes. Each class-group conformed an experimental group in order to affect the class-group dynamics as little as possible, avoiding changes that could have affected the intervention development. Thus, there were no changes in the children's school activities plan other than the addition of the mindfulness intervention.

During school year 2016-2017, sixth graders $(n=47)$ constituted a mindfulness intervention group with a trained mindfulness teacher (Mindful-Ch/Mindful-T, $n=15$ ), a mindfulness intervention group with a non-trained mindfulness teacher (Mindful-Ch/Non-Mindful-T, $n=13$ ), and a control group on which no intervention was made (Controls, $n=18$ ). All groups were evaluated before (to control that the groups did not differ in the study variables) and after a 13-weeks mindfulness intervention. The same procedure was repeated with fifth graders $(n=54)$ during school year 2017-2018 (Mindful-Ch/Mindful-T, $n=21$; MindfulCh/Non-Mindful-T, $n=20$; Controls, $n=13$ ).

Prior to the intervention, trained teachers were formed over 8 weekly 2-h sessions of mindfulness exercises based on the Mindfulness-Based Stress Reduction Program (MBSR) (Kabat-Zinn et al., 1992). See (Heredia et al., 2020a, b) for more information about the teacher's mindfulness training. Non-trained teachers had no experience with mindfulness and were just instructed to implement the children's intervention program.

The children's 13-weeks intervention consisted of 5-10 min mindfulness sessions before class, every day of the week. It included different mindfulness exercises specifically designed for children (for more detailed information please see Galla et al., 2016; GiménezDasí et al., 2016; Kaiser, 2010), divided into three main categories:

1. Anchoring in breathing, body and movement or others. This kind of exercises have been linked to enhanced executive functions (Hawkes et al., 2014). Exercises:

1.1 Mindfulness of Breathing, to settle both mind and body through breath awareness practice.

1.2 Counting from One to Ten on the Exhale, involving counting from one to ten on the exhalation and relaxing on the inhalation.

2. Open field / contemplative techniques, associated to improved non-cognitive-affective states (Desbordes et al., 2015). Exercises:

2.1 Sounds in Space, consisting of focusing attention and emotions on sounds of nature (Forest, Storm, Night, Wind and Sea) and OST such as Leroy Anderson's The Typewriter (Happiness), Brothers: A Tale of Two Sons Main Theme (Sadness), Vangelis's Mythodea (Anger / Activation), Jaws OST (Fear / Anxiety) and Carlos Sakai's Earth Spirit (Calm).

2.2 Open field with signals, where the attention is focused on any content going through the mind, with bell sounds as a guide.

3. Connection / Generative techniques with active interaction, related to positive affective states, such as lovingkindness and compassion meditations (Hutcherson et al., 2008). Exercises:

3.1 Funhouse Mirrors, consisting of the imitation of a partner's movements to experience moving in tandem with another person

3.2 Friendly wishes, where children were asked to write a list of good wishes or a poem.

All instructions for the intervention exercises were previously audio recorded by the investigators to be listened in the classroom. 


\section{Measures}

Pre- and post-intervention assessment was conducted using a neuropsychological battery of tests to evaluate changes in memory, attention and executive functions. Psychological questionnaires were also used to detect the effects of stressful events and a wide range of psychological problems in children. All of them were the latest available versions of reliable, valid, and widely used tools in neuropsychological assessment.

- RAVLT (Rey Auditory Verbal Learning Test) (Rey, 1964): assessment of verbal learning and memory, including proactive inhibition, retroactive inhibition, retention, encoding versus retrieval and subjective organization (Schmidt, 1996).It has adequate divergent and convergent validity and good reliability in terms of internal consistency (de Sousa Magalhães et al., 2012). Although internal consistency is not a comprehensive indicator of validity and reliability, in particular contexts it paves the way for proper interpretation (Alavi et al., 2021).

- Trails, Fluency and Interference subtests from ENFEN (Neuropsychological Evaluation of Executive Functions in Children) (Portellano et al., 2009): a standardised battery for the evaluation of the maturity level and cognitive performance in activities related to Executive Functions in children. The Trails subtest measures ability to plan, mental flexibility, working memory, prospective memory, visual-perceptual capacity, and motor fluency; the Fluency subtest assesses fluency, linguistic efficiency, categorization, updating, working memory, inhibition and sustained attention; and the Interference subtest measures inhibitory capacity, mental flexibility, exclusive attention and processing speed.

- Perception of Differences Test (Faces) (Thurstone \& Thurstone, 1941; Thurstone \& Yela, 2012): is a valid and reliable instrument validated in the Spanish population that evaluates focused and sustained attention and the ability to perceive similarities, differences and patterns.

- ROCF (Rey-Osterrieth complex figure test) (Osterrieth, 1944): is a valid, reliable and widely-used neuropsychological assessment tool for the evaluation of visuospatial constructional ability, visual memory and executive function mediated by the prefrontal lobe (Shin et al., 2006; Zhang et al., 2021).

- IECI (Children's Daily Stress Inventory) (Trianes et al., 2012): assessment of stressor stimuli and related psychophysiological, emotional, cognitive or behavioural responses with a Cronbach's alpha of 0.81 and a testretest reliability of 0.80 .
- SPECI (Screening of children's emotional and behavioural problems) (Garaigordobil \& Maganto, 2012): identifies the presence of emotional and behavioural problems in children between 5 and 12 years of age through 10 items: withdrawal, somatisation, anxiety, dependence, thinking problems, attention-hyperactivity, disruptive behaviour, academic performance, depression and violent behaviour with a Cronbach's alpha of 0.82 (Garaigordobil \& Maganto, 2014).

Almost all tests were self-reported by the study participants, except IECI and SPECI which were filled by the teachers.

Statistical analyses were carried out using Statistical Package for the Social Sciences Software (SPSS v.25). In order to investigate the effects of the mindfulness intervention, Student's t tests and Welch's ANOVA tests were used to compare the three groups of children. Non-parametric Dunnett's T3 post-hoc tests were used when groups showed nonnormal distributions. Significance levels were set at $\mathrm{p}<0.05$.

\section{Results}

\section{Pre- and Post-Intervention Neuropsychological and Psychological Assessment. Differences Between Mindful Experimental Groups (Mindful-Ch/ Mindful-T \& Mindful-Ch/Non-Mindful-T) and Controls}

Regarding pre-intervention assessment, no significant differences were found between groups, except for the Perception of Differences Test (Faces). Children of the control group detected more correct items $(M=44.09$; $S D=8.21)$ than those of the experimental group $(M=38.71$; $S D=13.02) ; t(89.679)=2.512, p<0.007$ (one-tailed). It should be noted that the differences detected on Faces test in the pre-intervention assessment disappeared after the mindful intervention.

In contrast, some significant results were found in the neuropsychological assessment after the 13-weeks mindfulness intervention. Table 1 displays an overview of the differences found between groups.

As Table 1 shows, the mindful experimental group performed significantly better than the control group on RAVLT free-recall test (from the second to the fifth trial). Accordingly, those children globally recalled more words from the A list than control children (A1 + A5) and made less repetition errors (a word that is given more than once in a trial). There were no observed differences for interference and retention trials among groups.

Statistically significant differences between groups were also observed in trails $\mathrm{A}$, where the mindful experimental 
Table 1 Comparison of results from the post-intervention assessment between mindful experimental groups and control group $(n=100)$

\begin{tabular}{|c|c|c|c|c|}
\hline \multirow[t]{2}{*}{ Test } & \multirow[t]{2}{*}{ Variable } & \multicolumn{2}{|l|}{ Group } & \multirow[t]{2}{*}{$\mathrm{p}$ value } \\
\hline & & $\begin{array}{l}\text { Control } \\
(n=31)\end{array}$ & $\begin{array}{l}\text { Mindful } \\
(n=69)\end{array}$ & \\
\hline \multirow[t]{7}{*}{ RAVLT } & Trial 1 & $7.03 \pm 1.74$ & $7.33 \pm 1.61$ & $0.394^{\mathrm{NS}}$ \\
\hline & Trial 2 & $9.03 \pm 2.05$ & $9.97 \pm 1.64$ & 0.017 \\
\hline & Trial 3 & $10.58 \pm 1.82$ & $12.06 \pm 1.53$ & $<0.001$ \\
\hline & Trial 4 & $11.74 \pm 1.76$ & $13.04 \pm 1.39$ & 0.001 \\
\hline & Trial 5 & $12.26 \pm 2.17$ & $14.01 \pm 1.01$ & $<0.001$ \\
\hline & $\begin{array}{l}\text { All trials } \\
\quad(\mathrm{A} 1+\mathrm{A} 5)\end{array}$ & $49.06 \pm 11.71$ & $56.43 \pm 5.79$ & 0.002 \\
\hline & Repetition & $3.45 \pm 2.51$ & $2.06 \pm 1.94$ & 0.003 \\
\hline Trails A & $\begin{array}{l}\text { Time (in } \\
\text { seconds) }\end{array}$ & $95.52 \pm 19.15$ & $76.93 \pm 17.06$ & $<0.001$ \\
\hline \multirow[t]{2}{*}{ ROCF } & $\begin{array}{l}\text { Time (in } \\
\text { seconds) }\end{array}$ & $141.39 \pm 43.04$ & $157.74 \pm 48.09$ & $0.109^{\mathrm{NS}}$ \\
\hline & $\begin{array}{l}\text { Drawing } \\
\text { score }\end{array}$ & $30.40 \pm 4.22$ & $31.96 \pm 3.27$ & 0.049 \\
\hline $\begin{array}{l}\text { Semantic } \\
\text { fluency } \\
\text { task }\end{array}$ & $\begin{array}{l}\text { Number of } \\
\text { animals in } \\
\text { one minute }\end{array}$ & $15.39 \pm 3.40$ & $18.19 \pm 3.98$ & 0.001 \\
\hline
\end{tabular}

Mean \pm SD; Student's T-test; $\mathrm{p}<0.05$

NS: Non-significant

group was faster than their peers; and in ROCF, with mindful children being more accurate in the drawing copy. This experimental group also performed better than controls in the Semantic fluency task, evoking more animals in one minute. Regarding all other neuropsychologicalvariables assessed, there were no differences between groups assessed (results not shown). In the same way, no significant differences were found on the psychological assessment between controls and their experimental peers concerning SPECI (Controls: $M=1.50, S D=1.849$; Experimental: $M=1.38, S D=1.1940$ ) and IECI (Controls: $M=5.34, S D=2.336$; Experimental: $M=4.81$, $S D=3.210)$ tests.
Pre- and Post-Intervention Neuropsychological and Psychological Assessment. Differences Between the Mindfulness Intervention Group with a Trained Mindfulness Teacher, the Mindfulness Intervention Group with a Non-Trained Mindfulness Teacher and the Control Group with no Intervention

As expected, no significant differences between the three groups were evident in the pre-intervention assessment, with the exception of the trial A4 of the RAVLT test. As shown in Table 2, children of the control group recalled more words in the RAVLT fourth trial than Mindful-Ch/Non-Mindful-T. There was a minor violation in homogeneity, but Welch's $F$ and Dunnett's Post hoc tests showed that this had no impact on the outcome.

Similarly to the previous results, statistically significant differences between the three groups were observed in the post-training assessment. Table 3 displays the summary statistics for those differences.

Regarding RAVLT free-recall test, the Mindful-Ch/NonMindful-T and the Mindful-Ch/Mindful-T groups recalled more words than the children of the control group on the third, fourth and fifth RAVLT trials. The Mindful-Ch/Mindful-T group recalled more words in total than the control group, and children from the Mindful-Ch/Non-Mindful-T were the ones that made less repetitions of words already said.

Mindful-Ch/Non-Mindful-T and Mindful-Ch/Mindful$\mathrm{T}$ groups were faster than controls in Trails $\mathrm{A}$, and the Mindful-Ch/Mindful-T group was the fastest among all groups in Trails B. In ROCF test, the Mindful-Ch/Mindful$\mathrm{T}$ group was more accurate in the free-hand drawings than controls, and both Mindful groups spent more time drawing than their control peers. Lastly, both ENFEN semantic fluency and formal lexical tasks were better performed by the Mindful-Ch/Mindful-T group, naming more animals and words beginning in "P" than participants of the control group. There wasn't any other difference between groups in the rest of the neuropsychological variables assessed (results not shown). It should be noted that there

Table 2 Comparison of results from the pre-intervention assessment between the mindfulness intervention group with a trained mindfulness teacher, the mindfulness intervention group with a non-trained mindfulness teacher and the control group $(n=100)$

\begin{tabular}{lllll}
\hline Test & Variable & Group & & p value \\
\cline { 2 - 4 } & & $\begin{array}{l}\text { Control } \\
(n=31)\end{array}$ & $\begin{array}{l}\text { Mindful-Ch /Non-Mindful- } \\
(n=33)\end{array}$ & $\begin{array}{l}\text { Mindful-Ch /Mindful-T } \\
(n=36)\end{array}$ \\
\hline RAVLT & A4 & $11.48 \pm 1.93^{\mathrm{a}}$ & $10.12 \pm 2.38^{\mathrm{b}}$ & $10.58 \pm 1.98^{\mathrm{ab}}$ \\
\hline
\end{tabular}

Mean \pm SD; Welch test \& T3 Dunnet post hoc test; $\mathrm{p}<0.05$

Not common letters $\left({ }^{\mathrm{a}, \mathrm{b}}\right)$ means differences between those groups 
Table 3 Comparison of results from the post-intervention assessment between the mindfulness intervention group with a trained mindfulness teacher, the mindfulness intervention group with a non-trained mindfulness teacher and the control group $(n=100)$

\begin{tabular}{|c|c|c|c|c|c|}
\hline \multirow[t]{2}{*}{ Test } & \multirow[t]{2}{*}{ Variable } & \multicolumn{3}{|l|}{ Group } & \multirow[t]{2}{*}{$\mathrm{p}$ value } \\
\hline & & $\begin{array}{l}\text { Control } \\
(n=31)\end{array}$ & $\begin{array}{l}\text { Mindful-Ch /Non- } \\
\text { Mindful-T } \\
(n=33)\end{array}$ & $\begin{array}{l}\text { Mindful-Ch /Mindful-T } \\
(n=36)\end{array}$ & \\
\hline \multirow[t]{7}{*}{ RAVLT } & Trial 1 & $7.03 \pm 1.74$ & $6.97 \pm 1.55$ & $7.67 \pm 1.60$ & $0.149^{\mathrm{NS}}$ \\
\hline & Trial 2 & $9.03 \pm 2.06$ & $9.75 \pm 1.52$ & $10.17 \pm 1.75$ & $0.064^{\mathrm{NS}}$ \\
\hline & Trial 3 & $10.58 \pm 1.82^{\mathrm{a}}$ & $11.87 \pm 1.50^{\mathrm{b}}$ & $12.22 \pm 1.57^{\mathrm{b}}$ & 0.001 \\
\hline & Trial 4 & $11.74 \pm 1.77^{\mathrm{a}}$ & $12.84 \pm 1.59^{\mathrm{b}}$ & $13.22 \pm 1.17^{\mathrm{b}}$ & 0.001 \\
\hline & Trial 5 & $12.26 \pm 2.17^{\mathrm{a}}$ & $13.97 \pm 0.90^{\mathrm{b}}$ & $14.06 \pm 1.12^{\mathrm{b}}$ & $<0.001$ \\
\hline & All trials (A1 + A5) & $50.65 \pm 7.67^{\mathrm{a}}$ & $53.72 \pm 11.22^{\mathrm{ab}}$ & $57.33 \pm 5.69^{\mathrm{b}}$ & 0.001 \\
\hline & Repetition & $3.45 \pm 2.51^{\mathrm{a}}$ & $1.75 \pm 1.95^{\mathrm{b}}$ & $2.33 \pm 1.91^{\mathrm{ab}}$ & 0.016 \\
\hline Trails A & Time (in seconds) & $95.52 \pm 19.15^{\mathrm{a}}$ & $79.52 \pm 18.98^{\mathrm{b}}$ & $74.62 \pm 15.04^{\mathrm{b}}$ & $<0.001$ \\
\hline Trails B & Time (in seconds) & $121.13 \pm 29.6^{\mathrm{a}}$ & $114.72 \pm 33.69^{\mathrm{ab}}$ & $105.64 \pm 19.45^{\mathrm{b}}$ & 0.043 \\
\hline \multirow[t]{2}{*}{ ROCF } & Time (in seconds) & $141.39 \pm 43.04^{\mathrm{a}}$ & $173.15 \pm 52.60^{\mathrm{b}}$ & $144.03 \pm 39.57^{\mathrm{b}}$ & 0.022 \\
\hline & Drawing score & $30.40 \pm 4.22^{\mathrm{a}}$ & $31.01 \pm 3.01^{\mathrm{ab}}$ & $32.79 \pm 3.30^{\mathrm{b}}$ & 0.020 \\
\hline Semantic fluency task & Number of animals in $1 \mathrm{~min}$ & $10.32 \pm 2.76^{\mathrm{a}}$ & $10.81 \pm 3.03^{\mathrm{ab}}$ & $12.25 \pm 2.98^{\mathrm{b}}$ & 0.001 \\
\hline Formal lexical task & $\begin{array}{l}\text { Number of words beginning in } \\
\text { "P" in } 1 \text { min }\end{array}$ & $15.39 \pm 3.40^{\mathrm{a}}$ & $17.16 \pm 3.67^{\mathrm{ab}}$ & $19.11 \pm 4.07^{\mathrm{b}}$ & 0.023 \\
\hline
\end{tabular}

Mean \pm SD; Welch test $\&$ T3 Dunnet post hoc test; $p<0.05$

Not common letters $\left({ }^{\mathrm{a}, \mathrm{b}}\right)$ means differences between those groups

NS: Non-significant

were no differences between children regarding stress or emotional and behavioural problems either (IECI and SPECI tests).

\section{Discussion}

The purpose of the current study was to explore the effects of a mindfulness-training school program for Spanish children on different neuropsychological and psychological measures.

According to our initial hypothesis, a consistent finding of this research is that the mindful experimental group performed better than their control peers in several neuropsychological tasks involving executive functions, such as Trails and Fluency subtests from ENFEN, and also in verbal learning (RAVLT) and visuospatial constructional ability (ROCF). Children from the Mindful-Ch/Mindful-T performed slightly better than those of the Mindful-Ch/NonMindful-T group, and both groups obtained better results than controls. These results suggest that mindfulness interventions in school settings may have beneficial effects on short-term auditory-verbal memory, learning and working memory (RAVLT); processing speed, visuomanual coordination, linguistic efficiency, alternating attention and working memory (ENFEN); and also visuospatial constructional ability (ROCF).
The data obtained also supports our hypothesis about the importance of the teacher's mindfulness training, as it seems that it can add a beneficial effect on the children's results. This is also supported by the work of other studies in this area, linking the teacher's mindfulness training and competences with improvements in effective classroom teaching practices, potentially impacting children's educational outcomes (Becker et al., 2017; Butterfield et al., 2020; Hirshberg et al., 2020; Khalilzadeh \& Khodi, 2021; Weare, 2019).

In accordance with the present results, previous studies in Western countries have identified that mindfulness interventions can improve executive functions on children, such as learning, memory, mental flexibility and processing, with moderate to large effect sizes (Diamond \& Lee, 2011; Flook et al., 2010; Takacs \& Kassai, 2019; Thierry et al., 2018). More specifically, a randomized controlled study examining the effect of mindfulness interventions on working memory found significant improvements in working memory capacity (Quach et al., 2016). Another investigation on working memory also reported a large positive correlation between mindfulness practice and working memory tasks in children (Natesh et al., 2014).

The findings of the present research regarding motor and visuospatial abilities also reflect those of recent investigations (Moreno-Gómez et al., 2020; Tarrasch et al., 2017), who also found that children practising mindfulness enhance visuospatial skills and motor accuracy. 
Another interesting finding of the present study is that no significant differences were found among groups in some tests of the neuropsychological assessment. There were no differences on the Perception of differences Test (Faces) that measures focused and sustained attention and the ability to perceive similarities, differences and patterns. However, it is important to note that the results from experimental and control children were aligned after the intervention and not at the beginning, meaning that mindful children improved their performance on the Faces test (although this was not statistically significant). In this regard, we found significant differences in alternating attention on ENFEN results, further supporting the idea that mindfulness practice may enhance attentional skills. Previous studies evaluating the effect of mindfulness-based interventions on this also observed consistent improvements on attention competence (Crescentini et al., 2016; Mak et al., 2018; Semple, 2010). However, there is no consensus about the direct implication of all types of attention in the mindfulness-practise effects (Sumantry \& Stewart, 2021).

There was also no difference on IECI assessing daily stress, and SPECI, evaluating withdrawal, somatisation, anxiety, dependence, thought problems, attention, hyperactivity, disruptive behaviour, academic performance, depression and violent behaviour. Some prior studies that have demonstrated the role of mindfulness in stress (Costello \& Lawler, 2014; van de Weijer-Bergsma et al., 2014), emotional and behavioural regulation (Joyce et al., 2010; Moreno-Gómez et al., 2020; Viglas \& Perlman, 2018), and academic performance (Güldal \& Satan, 2020; Miralles-Armenteros et al., 2021) on children, but in the present study no differences were detected in these measures. This result may be explained by the fact that both SPECI and IECI baseline data were low before the intervention, meaning that children presented previous low stress levels, and possibly minor emotional and behavioural problems. Probably for this reason, no changes were observed among participant and control groups on these variables. Another possible explanation could be related to the effective time of practice. In this sense, previous studies have showed a relation between practice time and psychological outcomes in adult population possibly mediated by the quality of practices (Goldberg et al., 2020; Ribeiro et al., 2018). The present study included 13-weeks intervention of 5-10 min mindfulness sessions before class with a limited number of different practices. In contrast, previous studies in children used different intervention contents and mostly more sessions of practice. Finally, this incongruence could be related to the test used. Previous studies reporting changes in both the stress and anxiety levels of children used different tests that could be more sensitive detecting these variables changes (PSS-10,SCARED-71) (Costello \& Lawler, 2014; van de Weijer-Bergsma et al., 2014).
As has been noted above, despite the growing body of mindfulness research in Western countries, little research has been carried out in Spain. The heterogeneity of the existing Spanish research in terms of participants, measures and intervention approaches makes it challenging to compare results, but the findings from this study make several contributions to the current paucity of literature in our country. The current study stands up some considerations to address when a mindful program wants to be implemented: the benefits of the teacher's mindfulness training, the necessity to adapt the mindful program to the age of the children and the integration of the mindful program in the class timetable. Moreover, it has been demonstrated in the Spanish children population that the present mindfulness program improves cognitive skills in children, executive functions and learning, such important skills for the child development and academic performance (Cortés Pascual et al., 2019; Visu-Petra et al., 2011). A recent Campbell's systematic review reported evidence about mindfulness interventions improving cognitive and socio-emotional outcomes, but found no support for improvement in behaviour or academic achievement (Maynard et al., 2017). However, the authors highlighted in particular the heterogeneity and weakness of the data produced by the studies. This reflects again the lack of adequate research about this matter and the need for further reliable evidence to evaluate the effectiveness of these interventions.

The major limitation of this study is that the three experimental groups were not randomized due to practical constraints, because children were clustered in their own classrooms. Another issue lies on the relatively short intervention, as the program only lasted for 13 weeks with 5 to 10 min of daily practice.

A key strength of the present study was the pre-/post-test design with a control condition to assess how effective was the intervention. Also, the mindfulness exercises were age appropriated and based on MBSR, the evidence-based program with the most empirical support (Felver et al., 2016). In this sense, it is important to note that mindfulness training for children must be adapted through age-appropriate activities, to address most effectively their developmental stages and needs (Bostic et al., 2015; Zelazo \& Lyons, 2012).

The other strengths of the present study included an adequate sample size as well, and the intervention was carried out in the classroom environment during school hours to facilitate the implementation and generalisation of the mindfulness program.

\section{Conclusions}

The present study was designed to determine the positive effects of a mindfulness intervention in children aged 9-11 in the Spanish school setting. The findings can contribute to 
a better understanding of the role of mindfulness practice in primary children regarding learning performance and executive functions. Also, the findings of this study have several practical implications in the classroom settings and in the teaching/learning process, in terms of the need inclusion of the practise in the school hours and for teachers to learn mindfulness themselves to apply the mindful interventions more effectively.

Overall, this study has provided a deeper insight into the effect of mindfulness-based interventions on children, given the fact that most of the existing literature has been carried out with adult populations. It also adds knowledge to the scarce body of research developed in Spain about this topic up to now.

Further studies need to be carried out in order to explore the benefits of mindfulness in children in classroom settings, focused particularly on neuropsychological performance and psychological well-being. It is also necessary to develop those studies with well randomized- control designs, longterm interventions and follow-up data to determine if there are sustained results over time.

Acknowledgements The authors wish to thank all teachers and participants for their contribution.

Authors' Contributions All authors contributed to the study conception and design. Material preparation, data collection and analysis were performed by Margarita Torrente, Laia Gasol, Paloma Vicens, Luis Heredia and Annabel Folch. The first draft of the manuscript was written by Annabel Folch and all authors commented on previous versions of the manuscript. All authors read and approved the final manuscript.

Funding Open Access funding provided thanks to the CRUE-CSIC agreement with Springer Nature.

Data Availability The datasets generated during and/or analysed during the current study are not publicly available due to school and parents request, but are available from the corresponding author on reasonable request.

\section{Declarations}

Ethics Approval This study was performed in line with the principles of the Declaration of Helsinki. Approval was granted by the Hospital Sant Joan de Reus and Hospital Joan XXIII de Tarragona ethical research committees (code number: 15-01-29/1proj1).

Consent Written informed consent was obtained from the parents.

Competing Interests The authors declare no competing interests.

Conflicts of Interest/Competing Interests All authors certify that they have no affiliations with or involvement in any organization or entity with any financial interest or non-financial interest in the subject matter or materials discussed in this manuscript.

Open Access This article is licensed under a Creative Commons Attribution 4.0 International License, which permits use, sharing, adaptation, distribution and reproduction in any medium or format, as long as you give appropriate credit to the original author(s) and the source, provide a link to the Creative Commons licence, and indicate if changes were made. The images or other third party material in this article are included in the article's Creative Commons licence, unless indicated otherwise in a credit line to the material. If material is not included in the article's Creative Commons licence and your intended use is not permitted by statutory regulation or exceeds the permitted use, you will need to obtain permission directly from the copyright holder. To view a copy of this licence, visit http://creativecommons. org/licenses/by/4.0/.

\section{References}

Alavi, S. M., Karami, H., \& Khodi, A. (2021). Examination of factorial structure of Iranian English language proficiency test: An IRT analysis of Konkur examination. Current Psychology. https://doi. org/10.1007/s12144-021-01922-1

Aucoin, M., Lalonde-Parsi, M., \& Cooley, K. (2014). Mindfulnessbased therapies in the treatment of functional gastrointestinal disorders: A meta-analysis. Evidence-Based Complementary and Alternative Medicine, 140724. https://doi.org/10.1155/2014/ 140724.

Bazzano, A. N., Anderson, C. E., Hylton, C., \& Gustat, J. (2018). Effect of mindfulness and yoga on quality of life for elementary school students and teachers: Results of a randomized controlled schoolbased study. Psychology Research and Behavior Management, 11, 81-89. https://doi.org/10.2147/PRBM.S157503

Becker, B. D., Gallagher, K. C., \& Whitaker, R. C. (2017). Teachers' dispositional mindfulness and the quality of their relationships with children in Head Start classrooms. Journal of School Psychology, 65, 40-53. https://doi.org/10.1016/j.jsp.2017.06.004

Blair, C. (2016). Executive function and early childhood education. Current Opinion in Behavioral Sciences, 10, 102-107. https:// doi.org/10.1016/j.cobeha.2016.05.009

Bostic, J. Q., Nevarez, M. D., Potter, M. P., Prince, J. B., Benningfield, M. M., \& Aguirre, B. A. (2015). Being present at school: Implementing mindfulness in schools. Child and Adolescent Psychiatric Clinics of North America, 24(2), 245-259. https://doi.org/10. 1016/j.chc.2014.11.010

Brenner, J., LeBlang, S., Lizotte-Waniewski, M., Schmidt, B., Espinosa, P. S., DeMets, D. L., et al. (2020). Mindfulness with paced breathing reduces blood pressure. Medical Hypotheses, 142, 109780. https://doi.org/10.1016/j.mehy.2020.109780

Butterfield, K. M., Roberts, K. P., Feltis, L. E., \& Kocovski, N. L. (2020). What is the evidence in evidence-based mindfulness programs for children? Advances in Child Development and Behavior, 58, 189-213. https://doi.org/10.1016/bs.acdb.2020.01.007

Calvete, E., \& Royuela-Colomer, E. (2016). Measurement of dispositional mindfulness in children and adolescents: A review of available self-report measures in Spanish. Mindfulness \& Compassion, 1(2), 58-67. https://doi.org/10.1016/j.mincom.2016.11.001

Cordeiro, C., Magalhães, S., Rocha, R., Mesquita, A., Olive, T., Castro, S. L., \& Limpo, T. (2021). Promoting third graders' executive functions and literacy: A pilot study eamining the benefits of mindfulness vs. relaxation training. Frontiers in Psychology, 12, 643794. https://doi.org/10.3389/fpsyg.2021.643794

Cortés Pascual, A., Moyano Muñoz, N., \& Quílez Robres, A. (2019). The relationship between executive functions and academic performance in primary education: Review and meta-analysis. Frontiers in Psychology, 11(10), 1582. https://doi.org/10.3389/fpsyg. 2019.01582

Costello, E., \& Lawler, M. (2014). An exploratory study of the effects of mindfulness on perceived levels of stress among 
school-children from lower socioeconomic backgrounds. The International Journal of Emotional Education, 6(2), 21-39.

Crescentini, C., Capurso, V., Furlan, S., \& Fabbro, F. (2016). Mindfulness-oriented meditation for primary school children: Effects on attention and psychological well-being. Frontiers in Psychology, 7, 805. https://doi.org/10.3389/fpsyg.2016.00805

Creswell, J. D., Lindsay, E. K., Villalba, D. K., \& Chin, B. (2019). Mindfulness training and physical health. Psychosomatic Medicine, 81(3), 224-232. https://doi.org/10.1097/PSY.0000000000 000675

Dahlgaard, J., Jørgensen, M. M., van der Velden, A. M., Sumbundu, A., Gregersen, N., Olsen, R. K., \& Mehlsen, M. Y. (2018). Mindfulness, Health, and Longevity. In S. I. S. Rattan, \& M. Kyriazis (Eds.), The Science of Hormesis in Health and Longevity (1st ed., pp. 243-255). Elsevier. https://doi.org/10.1016/B978-0-12814253-0.00022-X.

Deng, X., Zhang, J., Hu, L., \& Zeng, H. (2019). Neurophysiological evidences of the transient effects of mindfulness induction on emotional processing in children: An ERP study. International Journal of Psychophysiology, 143, 36-43. https://doi.org/10. 1016/j.ijpsycho.2019.06.014

Desbordes, G., Gard, T., Hoge, E. A., Hölzel, B. K., Kerr, C., Lazar, S. W., et al. (2015). Moving beyond mindfulness: Defining equanimity as an otcome measure in meditation and contemplative research. Mindfulness, 6(2), 356-372. https://doi.org/ 10.1007/s12671-013-0269-8

de Sousa Magalhães, S., Malloy-Diniz, L. F., \& Hamdan, A. C. (2012). Validity convergent and reliability test-retest of the rey auditory verbal learning test. Clinical Neuropsychiatry: Journal of Treatment Evaluation, 9(3), 129-137.

Diamond, A., \& Lee, K. (2011). Interventions shown to aid executive function development in children 4 to 12 years old. Science, 333(6045), 959-964. https://doi.org/10.1126/science.1204529

Felver, J. C., Celis-de Hoyos, C. E., Tezanos, K., \& Singh, N. N. (2016). A systematic review of mindfulness-based interventions for youth in school settings. Mindfulness, 7(1), 34-45. https:// doi.org/10.1007/s12671-015-0389-4

Flook, L., Smalley, S. L., Kitil, M. J., Galla, B. M., Kaiser-Greenland, S., Locke, J., et al. (2010). Effects of mindful awareness practices on executive functions in elementary school children. Journal of Applied School Psychology, 26(1), 70-95. https:// doi.org/10.1080/15377900903379125

Galla, B. M., Kaiser-Greenland, S., \& Black, D. S. (2016). Mindfulness Training to Promote Self-Regulation in Youth: Effects of the Inner Kids Program. In: K., Schonert-Reichl, \& R., Roeser (eds), Handbook of Mindfulness in Education. Mindfulness in Behavioral Health. Springer. https://doi.org/10.1007/978-14939-3506-2_19.

Garaigordobil, M., \& Maganto, C. (2012). SPECI. Screening de Problemas Emocionales y de Conducta Infantil (1st ed.). TEA Ediciones.

Garaigordobil, M., \& Maganto, C. (2014). Speci. Screening de problemas emocionales y de conducta infantil: descripción y datos psicométricos. International Journal of Developmental and Educational Psychology, 1(4), 319-328.

Geronimi, E. M. C., Arellano, B., \& Woodruff-Borden, J. (2020). Relating mindfulness and executive function in children. Clinical Child Psychology and Psychiatry, 25(2), 435-445. https:// doi.org/10.1177/1359104519833737

Giménez-Dasí, M., Quintanilla Cobián, L., \& Arias Vega, L. (2016). Pensando las emociones con atención plena (1st ed.). Ediciones Pirámide.

Goldberg, S. B., Knoeppel, C., Davidson, R. J., \& Flook, L. (2020). Does practice quality mediate the relationship between practice time and outcome in mindfulness-based stress reduction? Journal of Counseling Psychology, 67(1), 115-122.
Gong, H., Ni, C.-X., Liu, Y.-Z., Zhang, Y., Su, W.-J., Lian, Y.-J., et al. (2016). Mindfulness meditation for insomnia: A metaanalysis of randomized controlled trials. Journal of Psychosomatic Research, 89, 1-6. https://doi.org/10.1016/j.jpsychores. 2016.07.016

Greeson, J. M., Zarrin, H., Smoski, M. J., Brantley, J. G., Lynch, T. R., Webber, D. M., et al. (2018). Mindfulness meditation targets transdiagnostic symptoms implicated in stress-related disorders: Understanding relationships between changes in mindfulness, sleep quality, and physical symptoms. Evidence-Based Complementary and Alternative Medicine, 4505191. https://doi.org/10. 1155/2018/4505191.

Grossman, P., Niemann, L., Schmidt, S., \& Walach, H. (2004). Mindfulness-based stress reduction and health benefits: A meta-analysis. Journal of Psychosomatic Research, 57(1), 35-43. https:// doi.org/10.1016/S0022-3999(03)00573-7

Guendelman, S., Medeiros, S., \& Rampes, H. (2017). Mindfulness and emotion regulation: Insights from neurobiological, psychological, and clinical studies. Frontiers in Psychology, 8, 220. https://doi. org/10.3389/fpsyg.2017.00220

Guerra, J., García-Gómez, M., Turanzas, J., Cordón, J. R., SuárezJurado, C., \& Mestre, J. M. (2019). A brief spanish version of the Child and Adolescent Mindfulness Measure (CAMM). A dispositional mindfulness measure. International Journal of Environmental Research and Public Health, 16(8), 1355. https://doi.org/ 10.3390/ijerph16081355

Güldal, Ş., \& Satan, A. (2020). The effect of mindfulness based psychoeducation program on adolescents' character strengths, mindfulness and academic achievement. Current Psychology, 1-12. https://doi.org/10.1007/s12144-020-01153-w.

Hawkes, T. D., Manselle, W., \& Woollacott, M. H. (2014). Tai Chi and meditation-plus-exercise benefit neural substrates of executive function: A cross-sectional, controlled study. Journal of Complementary and Integrative Medicine, 11(4), 279-288. https://doi. org/10.1515/jcim-2013-0031

Heredia, L., Torrente, M., \& Vicens, P. (2020a). Spiritual competence, contemplative education and mindfulness in schools. Studies in Psychology, 44(3), 467-289.

Heredia, L., Ventura, D., Torrente, M., \& Vicens, P. (2020b). A mindfulness-based training program for teachers increases dispositional mindfulness, cognitive flexibility and inhibitory control. Submitted for publication.

Hirshberg, M. J., Flook, L., Enright, R. D., \& Davidson, R. J. (2020). Integrating mindfulness and connection practices into preservice teacher education improves classroom practices. Learning and Instruction, 66, 101298. https://doi.org/10.1016/j.learninstruc. 2019.101298

Hofmann, S. G., \& Gómez, A. F. (2017). Mindfulness-based interventions for anxiety and depression. Psychiatric Clinics of North America, 40(4), 739-749. https://doi.org/10.1016/j.psc.2017.08. 008

Hofmann, S. G., Sawyer, A. T., Witt, A. A., \& Oh, D. (2010). The effect of mindfulness-based therapy on anxiety and depression: A metaanalytic review. Journal of Consulting and Clinical Psychology, 78(2), 169-183. https://doi.org/10.1037/a0018555

Hutcherson, C. A., Seppala, E. M., \& Gross, J. J. (2008). Loving-kindness meditation increases social connectedness. Emotion, 8(5), 720-724. https://doi.org/10.1037/a0013237

Ie, A., Ngnoumen, C. T., \& Langer, E. J. (2014). Origins and Theory. In A. Ie, C. T. Ngnoumen, \& E. J. Langer (Eds.), The Wiley Blackwell Handbook of Mindfulness (pp. 1-5). Wiley. https://doi.org/ 10.1002/9781118294895.part1.

Joyce, A., Etty-Leal, J., Zazryn, T., Hamilton, A., \& Hassed, C. (2010). Exploring a mindfulness meditation program on the mental health of upper primary children: A pilot study. Advances in School 
Mental Health Promotion, 3(2), 17-25. https://doi.org/10.1080/ 1754730X.2010.9715677

Kabat-Zinn, J., Massion, A. O., Kristeller, J., Peterson, L. G., Fletcher, K. E., Pbert, L., et al. (1992). Effectiveness of a meditation-based stress reduction program in the treatment of anxiety disorders. American Journal of Psychiatry, 149(7), 936-943. https://doi.org/ 10.1176/ajp.149.7.936

Kaiser, S. (2010). The Mindful Child. How to Help your Kid Manage Stress and Become Happier, Kinder and More Compassionate. Simon \& Schuster, Inc.

Kearney, D. J., McDermott, K., Martinez, M., \& Simpson, T. L. (2011). Association of participation in a mindfulness programme with bowel symptoms, gastrointestinal symptom-specific anxiety and quality of life. Alimentary Pharmacology \& Therapeutics, 34(3), 363-373. https://doi.org/10.1111/j.1365-2036.2011.04731.x

Khalilzadeh, S., \& Khodi, A. (2021). Teachers' personality traits and students' motivation: A structural equation modeling analysis. Current Psychology, 40, 1635-1650. https://doi.org/10.1007/ s12144-018-0064-8

Khoury, B., Sharma, M., Rush, S. E., \& Fournier, C. (2015). Mindfulness-based stress reduction for healthy individuals: A metaanalysis. Journal of Psychosomatic Research, 78(6), 519-528. https://doi.org/10.1016/j.jpsychores.2015.03.009

Mak, C., Whittingham, K., Cunnington, R., \& Boyd, R. N. (2018). Efficacy of mindfulness-based interventions for attention and executive function in children and adolescents-a systematic review. Mindfulness, 9, 59-78. https://doi.org/10.1007/ s12671-017-0770-6

Maynard, B. R., Solis, M., Miller, V. L., \& Brendel, K. E. (2017). Mindfulness-based interventions for improving cognition, academic achievement, behavior, and socioemotional functioning of primary and secondary school students. Campbell Systematic Reviews, 13,1-144.

Medical Subject Headings. (2014). Mindfulness - MeSH - NCBI. https://www.ncbi.nlm.nih.gov/mesh/?term=mindfulness. Accessed 23 April 2020.

Miralles-Armenteros, S., Chiva-Gómez, R., Rodríguez-Sánchez, A., \& Barghouti, Z. (2021). Mindfulness and academic performance: The role of compassion and engagement. Innovations in Education and Teaching International, 58(1), 3-13. https://doi.org/10. 1080/14703297.2019.1676284

Moreno-Gómez, A., \& Cejudo, J. (2019). Effectiveness of a mindfulness-based social-emotional learning program on psychosocial adjustment and neuropsychological maturity in kindergarten children. Mindfulness, 10(1), 111-121. https://doi.org/10.1007/ s12671-018-0956-6

Moreno-Gómez, A., Luna, P., \& Cejudo, J. (2020). Promoting school success through mindfulness-based interventions in elementary education: Mindkinder program. Revista De Psicodidactica, 25(2), 206-356. https://doi.org/10.1016/j.psicod.2019.12.001

Natesh, B., Rajesh, S. K., \& Nagendra, H. R. (2014). Relationship between state mindfulness and working memory in children. Indian Journal of Positive Psychology, 5(3), 310.

Osterrieth, P. (1944). Le test de copie d'une figure complexe; contribution a l'etude de la perception et de la memoire. [Test of copying a complex figure; contribution to the study of perception and memory]. Archives De Psychologie, 30, 206-356.

Pascoe, M. C., Thompson, D. R., Jenkins, Z. M., \& Ski, C. F. (2017). Mindfulness mediates the physiological markers of stress: Systematic review and meta-analysis. Journal of Psychiatric Research, 95, 156-178. https://doi.org/10.1016/j.jpsychires.2017.08.004

Pinazo, D., García-Prieto, L. T., \& García-Castellar, R. (2020). Implementation of a program based on mindfulness for the reduction of aggressiveness in the classroom. Revista De Psicodidáctica (english Ed.), 25(1), 30-35. https://doi.org/10.1016/j.psicoe.2019. 08.003
Portellano, J., Martínez, R., \& Zumárraga, L. (2009). ENFEN. Evaluación Neuropsicológica de las Funciones Ejecutivas en Niños. TEA Ediciones.

Quach, D., Jastrowski Mano, K. E., \& Alexander, K. (2016). A Randomized controlled trial examining the effect of mindfulness meditation on working memory capacity in adolescents. Journal of Adolescent Health, 58(5), 489-496. https://doi.org/10.1016/j. jadohealth.2015.09.024

Remmers, C., Topolinski, S., \& Koole, S. L. (2016). Why being mindful may have more benefits than you realize: Mindfulness improves both explicit and implicit mood regulation. Mindfulness, 7(4), 829-837. https://doi.org/10.1007/s12671-016-0520-1

Renshaw, T. L., \& Cook, C. R. (2017). Introduction to the special issue: Mindfulness in the schools-historical roots, current status, and future directions. Psychology in the Schools, 54(1), 5-12. https:// doi.org/10.1002/pits.21978

Rey, A. (1964). L' Examen Clinique en Psychologie. Rey Auditory Verbal Learning Test [The Clinical Psychological Examination] (2nd ed.). Presses Universitaire de France.

Ribeiro, L., Atchley, R. M., \& Oken, B. S. (2018). Adherence to practice of mindfulness in novice meditators: Practices chosen, amount of time practiced, and long-term effects following a mindfulness-based intervention. Mindfulness, 9, 401-411.

Rusch, H. L., Rosario, M., Levison, L. M., Olivera, A., Livingston, W. S., Wu, T., \& Gill, J. M. (2019). The effect of mindfulness meditation on sleep quality: A systematic review and meta-analysis of randomized controlled trials. Annals of the New York Academy of Sciences, 1445(1), 5-16. https://doi.org/10.1111/nyas.13996

Schmidt, M. (1996). Rey Auditory Verbal Learning Test - RAVLT: a Handbook. Western Psychological Services.

Schonert-Reichl, K. A., \& Roeser, R. W. (2016). Handbook of Mindfulness in Education: Integrating Theory and Research into Practice (1 st ed.). Springer. https://doi.org/10.1007/978-1-4939-3506-2.

Semenov, A.D.; Kennedy, D., \& Zelazo, P.D. (2020). Mindfulness and executive function. Implications for learning and early childhood Education. In M. S. C. Thomas, D. Mareschal, \& I. Dumontheil (Eds.), Educational Neuroscience: Development Across the Life Span ( pp 34). Routledge.

Semple, R. J. (2010). Does mindfulness meditation enhance attention? A randomized controlled trial. Mindfulness, 1(2), 121-130. https://doi.org/10.1007/s12671-010-0017-2

Shin, M. S., Park, S. Y., Park, S. R., Seol, S. H., \& Kwon, J. S. (2006). Clinical and empirical applications of the rey-osterrieth complex figure test. Nature Protocols, 1(2), 892-899. https://doi.org/10. 1038/nprot.2006.115

Sibinga, E. M. S., Webb, L., Ghazarian, S. R., \& Ellen, J. M. (2016) School-based mindfulness instruction: An RCT. Pediatrics, 137(1). https://doi.org/10.1542/peds.2015-2532

Sumantry, D., \& Stewart, K. E. (2021). Meditation, mindfulness, and attention: A meta-analysis. Mindfulness, 12, 1332-1349. https:// doi.org/10.1007/s12671-021-01593-w

Takacs, Z. K., \& Kassai, R. (2019). The efficacy of different interventions to foster children's executive function skills: A series of meta-analyses. Psychological Bulletin, 145(7), 653-697. https:// doi.org/10.1037/bul0000195

Tarrasch, R., Margalit-Shalom, L., \& Berger, R. (2017). Enhancing visual perception and motor accuracy among school children through a mindfulness and compassion program. Frontiers in Psychology, 8, 281. https://doi.org/10.3389/fpsyg.2017.00281

Thierry, K. L., Vincent, R. L., Bryant, H. L., Kinder, M. B., \& Wise, C. L. (2018). A self-oriented mindfulness-based curriculum improves prekindergarten students' executive functions. Mindfulness, 9(5), 1443-1456. https://doi.org/10.1007/s12671-018-0888-1

Thurstone, L. L., \& Thurstone, T. (1941). Factorial studies of intelligence. Psychometric Monographs, 2(94). https://psycnet.apa.org/ record/1941-03743-001 
Thurstone, L. L., \& Yela, M. (2012). Caras-R. Test de Percepción de Diferencias-Revisado. TEA Ediciones.

Trianes, M., Blanca, M., Fernández-Baena F.J., Escobar, M., \& Maldonado, E. F. (2012). IECI. Inventario de Estrés Cotidiano Infantil (1st ed.). TEA Ediciones.

van de Weijer-Bergsma, E., Langenberg, G., Brandsma, R., Oort, F. J., \& Bögels, S. M. (2014). The effectiveness of a school-based mindfulness training as a program to prevent stress in elementary school children. Mindfulness, 5(3), 238-248. https://doi.org/10. 1007/s12671-012-0171-9

Ven. Bhikkhu Bodhi. (2016). The Transformations of Mindfulness. In R. E., Purser, D. Forbes, \& A. Burke (Eds.), Handbook of Mindfulness. Culture, Context, and Social Engagement (pp. 3-14). Berlin: Springer. https://doi.org/10.1007/978-3-319-44019-4_1.

Viglas, M., \& Perlman, M. (2018). Effects of a mindfulness-based program on young children's self-regulation, prosocial behavior and hyperactivity. Journal of Child and Family Studies, 27(4), 1150-1161. https://doi.org/10.1007/s10826-017-0971-6

Viñas, F., Malo, S., González, M., Navarro, D., \& Casas, F. (2015). Assessing mindfulness on a sample of catalan-speaking Spanish adolescents: Validation of the catalan version of the child and adolescent mindfulness measure. The Spanish Journal of Psychology, 18(E46), 1-8. https://doi.org/10.1017/sjp.2015.48

Visu-Petra, L., Cheie, L., Benga, O., \& Miclea, M. (2011). Cognitive control goes to school: The impact of executive functions on academic performance. Procedia - Social and Behavioral Sciences, $11,240-244$.

Weare, K. (2019). Mindfulness and contemplative approaches in education. Current Opinion in Psychology, 28, 321-326. https://doi.org/ 10.1016/j.copsyc.2019.06.001
Wheeler, M. S., Arnkoff, D. B., \& Glass, C. R. (2017). The neuroscience of mindfulness: How mindfulness alters the brain and facilitates emotion regulation. Mindfulness, 8, 1471-1487. https://doi. org/10.1007/s12671-017-0742-x

Zelazo, P. D., \& Lyons, K. E. (2012). The potential benefits of mindfulness training in early childhood: A developmental social cognitive neuroscience perspective. Child Development Perspectives, 6(2), 154-160. https://doi.org/10.1111/j.1750-8606.2012.00241.x

Zenner, C., Herrnleben-Kurz, S., \& Walach, H. (2014). Mindfulnessbased interventions in schools - a systematic review and metaanalysis. Frontiers in Psychology, 5, 603. https://doi.org/10.3389/ fpsyg.2014.00603

Zhang, X., Lv, L., Min, G., Wang, Q., Zhao, Y., \& Li, Y. (2021). Overview of the complex figure test and its clinical application in neuropsychiatric disorders, including copying and recall. Frontiers in Neurology, 12, 680474. https://doi.org/10.3389/fneur.2021. 680474

Zoogman, S., Goldberg, S. B., Hoyt, W. T., \& Miller, L. (2015). Mindfulness Interventions with youth: A meta-analysis. Mindfulness, 6(2), 290-302. https://doi.org/10.1007/s12671-013-0260-4

Publisher's Note Springer Nature remains neutral with regard to jurisdictional claims in published maps and institutional affiliations. 